\title{
GCU
}

Glasgow Caledonian

University

University for the Common Good

\section{A universal climate-based energy and thermal expectation index: initial development and tests}

Emmanuel, Rohinton; Kumar, Bimal; Roderick, Ya; McEwan, David

Published in:

Energy and Buildings

DOI:

10.1016/j.enbuild.2012.12.008

Publication date:

2013

Document Version

Author accepted manuscript

Link to publication in ResearchOnline

Citation for published version (Harvard):

Emmanuel, R, Kumar, B, Roderick, Y \& McEwan, D 2013, 'A universal climate-based energy and thermal expectation index: initial development and tests', Energy and Buildings, vol. 58, pp. 208-218.

https://doi.org/10.1016/j.enbuild.2012.12.008

\section{General rights}

Copyright and moral rights for the publications made accessible in the public portal are retained by the authors and/or other copyright owners and it is a condition of accessing publications that users recognise and abide by the legal requirements associated with these rights.

Take down policy

If you believe that this document breaches copyright please view our takedown policy at https://edshare.gcu.ac.uk/id/eprint/5179 for details of how to contact us. 


\title{
A universal climate-based energy and thermal expectation index: Initial development and tests
}

\author{
R Emmanuel ${ }^{a^{*}}$, B Kumar $^{\mathrm{b}}$, Ya Roderick $^{\mathrm{c}}$, D McEwan $^{\mathrm{d}}$ \\ ${ }^{a}$ Dept of Construction and Surveying, School of Engineering and the Built Environment, Glasgow \\ Caledonian University, UK. Email: Rohinton.Emmanuel@gcu.ac.uk \\ ${ }^{b}$ Dept of Construction and Surveying, School of Engineering and the Built Environment, Glasgow \\ Caledonian University, UK. Email: B.Kumar@gcu.ac.uk \\ 'Integrated Environmental Solutions (IES) Ltd., Helix Building, Kelvin Campus, West of Scotland \\ Science Park, Glasgow G20 0SP, UK. Email: ya.roderick@iesve.com \\ dIntegrated Environmental Solutions (IES) Ltd., Helix Building, Kelvin Campus, West of Scotland \\ Science Park, Glasgow G20 0SP, UK. Email: david.mcewan@iesve.com \\ *Corresponding author. \\ Address: Dept of Construction and Surveying, School of Engineering and the Built Environment, \\ Glasgow Caledonian University, 70 Cowcaddens Road, Glasgow G4 OBA, UK \\ Tel: $+44(0) 1413313217$ \\ Fax: $+44(0) 1413313370$
}

\begin{abstract}
We protoyped a set of energy indices that can be used to assess, classify and compare any worldwide climate (weather data or extrapolated climate change data) to understand its energy burden on buildings and for the use in sustainable building design. The indices are intended as rapid and interactive holistic design tools applicable to any building type, with any design strategy, in any location worldwide and for the simple quantification of the impact of climate change on building energy use over its lifecycle. The indices are based on the fact that climate underlies building energy use and it is therefore possible to compare designs relative to climate, visualize where design emphasis needs to be placed and directly and interactively track the effect of design strategies.
\end{abstract}

We then test them against the well-known Mahoney's Table as well as against other parametric simulation software to evaluate their robustness and applicability in a wide variety of climatic contexts from around the world. The index works well in most climates except hot, humid ones. Lessons for future development and implementation are discussed.

\section{Key words}

Climate Energy Index, Building Energy Index, building simulation, IES-Virtual Environment 


\section{Introduction}

Buildings are designed to create a suitable internal environment for human comfort. The successful design of comfortable buildings relies on an appropriate understanding of the climate. Climate underlies building energy use, therefore a climate-responsive building design is the key to achieve a comfortable yet energy efficient building environment. However, in practice, it is difficult to translate climate data into meaningful information that can capture the local climatic characteristics. There have been numerous attempts to establish a relationship between comfort, climate and built form and to explore various climatic design strategies. These approaches are limited in a variety of ways such as to certain building types or climate types. In addition, these approaches are still relatively complex and require either a high level of interpretation to be correctly utilised in the design process or vast amounts of data to be of practical use.

In order to overcome these difficulties a set of globally applicable energy indices have been developed by the Integrated Environmental Systems Ltd (IES) - makers of the dynamic thermal simulation software IES Virtual Environment (IES VE). The indices - Climate Energy Index (CEI) and Building Energy Index (BEI) - are interactive holistic design tools to assess, clarify and compare any worldwide climate data and hence to quantify the climate impact on building energy performance.

The Climate Energy Index (CEI) provides an indication of the consequence or 'energy burden' of climate with respect to building performance at an accepted standard of comfort at a particular geographic location. It represents an annual sum of energy required to condition $1 \mathrm{~m}^{3}$ of air at any weather hourly ordinate to the nearest boundary of a human comfort zone. The human comfort zone is determined based on ISO 7730 occupant comfort standard using Predicted Mean Vote (PMV). Although there are other approaches to thermal comfort ISO 7730 represents the most widely used comfort standard around the world. The Building Energy Index (BEI) is an overall performance indicator for building design strategy. It comprises the climate related and climate 
unrelated energy loads. The BEI can be compared directly with simulated or measured energy consumption data of a proposed building to benchmark its energy performance.

In this paper we present these indices and perform validity and robustness tests by comparing the indices against well-known previous works as well as simulated building energy consumption data for 10 different buildings in 14 different geographic locations around the world. Implications for future development and work are explored.

\section{Background}

\section{$\underline{2.1 \text { History of energy indices for buildings }}$}

Efforts to quantify normative energy consumption in buildings (especially housing) began with the energy crisis in the 1970s. Given the wide disparity in energy consumption patterns even within the developed world and the importance of the built environment in reducing national energy consumption, there was a need to benchmark building energy performance with a view to standardize and codify the best practices. Such indices are usually expressed in normalised energy units $\left(\right.$ such as $\left.\mathrm{kWh} / \mathrm{m}^{2}\right)[1]$. A review of early attempts to develop energy indices is given by Yannas [2].

One of the early 'energy indices' was developed by Yannas [3]. According to this index (called the Energy Index - El), a notional detached dwelling complying with the 1990 UK Building regulations would consume approximately 100-115 kWh per annum per $\mathrm{m}^{2}$ of floor area. A building fulfilling all the known 'good design' principles (i.e. south facing windows, double glazing, insulated walls and roofs, tight construction - 0.5 Air Changes per hour $[\mathrm{ACH}]$ and mechanical ventilation with heat recovery) will have an El of less than $30 \mathrm{kWh} / \mathrm{year} / \mathrm{m}^{2}$ [4]. This compares well with the most stringent current standards (for example the Passivhus standards [5] $-15 \mathrm{kWh} / \mathrm{year} / \mathrm{m}^{2}$ or the UK Code for Sustainable Homes [6] - $45 \mathrm{kWh} / \mathrm{year} / \mathrm{m}^{2}$ ). 
Attempts to quantify the 'climate burden' imposed by external climate on buildings have an even longer history. Early attempts from the time of Silpasastra in India [7] and Vitruvius [8] in Rome focused on intuitively developed design exemplars based on climate types. An early approach based on meteorological data was first attempted by Mahoney in 1965 [9]. We will return to this method later in the analysis.

\subsection{Recent developments in building/climate indices}

The consumption of energy in buildings continues to rise. Buildings account for $20-40 \%$ of the total final energy consumption in developed economies [10] but this could be as high as $70 \%$ in developing countries [11]. This has led to a proliferation of building energy standards. A survey in 1994 [12] found 27 countries had mandatory energy standards (a further 11 had voluntary or mixed standards) among the 57 countries surveyed; this has risen to 40 countries (mandatory standards) and 21 (voluntary or mixed) in 2009 [13]. A further 11 countries had proposed new building energy standards. The growth in developing countries is particularly striking: a more recent survey [14] found over 60 developing countries now have mandatory or voluntary standards. Such standards invariably require performance benchmarks in the form of energy and/or climate indices.

An index to assess the climatic suitability of different U.S. climates for natural ventilation of commercial buildings was developed by Axley and Emmerich [15]. A computer tool based on this methodology is also available [16] for U.S. climates. Despite this, recent efforts to quantify the 'energy burden' of climates are relatively rare.

However, there are many recent efforts to develop indices to benchmark building energy needs. An overview of efforts in the EU is provided by Thomsen and Wittchen [17]. A simple energy index called Normalised Energy Use Index (NEUI) was developed for Brazilian buildings [18]. NEUI uses simulated building energy use and normalises it using a function dependent on outdoor temperature. Comparisons with a Brazilian building showed good agreement. 
A key need in devising building energy indices is to include the so-called 'lifecycle energy needs' (energy use in construction to demolition, and energy embodied in buildings). In the face of increasing demands for low/zero energy buildings, the latter (embodied energy) could become an important part of the total energy used in buildings. This is not addressed by most of the current building energy assessment or rating methods. A methodology to develop a lifecycle energy index is proposed by Hernandez and Kenny [19].

A further confounding factor is the increasingly complicated nature of building energy use evaluation systems. A recent proposal [20] to develop a weighted energy index for buildings suggested 25 indicators in 6 categories ranging from heating/cooling load, equipment efficiency, embodied energy in building materials, operational and management functions, renewable energy and indoor climate and health.

\subsection{The proposed CEI/BEI}

The CEI/BEI developed by the IES Ltd is an attempt to quantify the energy burden on a building by outside air. It has four component loads: two sensible energy loads (heating and cooling) and two latent energy needs (humidification and dehumidification). The CEI is defined thus:

$$
\text { CEI = Sum of (Sensible Cooling, Sensible Heating, Humidification, dehumidification). }
$$

It is expressed in $\mathrm{kWh} / \mathrm{yr}$ for a given volume of air (in $\mathrm{m}^{3} / \mathrm{hr}$ ). Table 1 presents the CEI values for 14 representative geographical locations from around the world.

[Table 1 approximately here]

The Building Energy Index (BEI) expresses the CEI in terms of energy need of a given building.

$$
B E I=\frac{C E I}{O A \times F A}
$$

where, $\quad$ BEl= Building Energy Index $\left(\mathrm{kWh} / \mathrm{yr} / \mathrm{m}^{2}\right)$; 
$O A=$ Outside air intake (both infiltration and auxiliary ventilation $\left(\mathrm{m}^{3} / \mathrm{hr}\right)$;

$\mathrm{FA}=$ Floor area $\left(\mathrm{m}^{2}\right)$

\section{Method}

\subsection{IES VE Platform}

The Climate Energy Index (CEI) and Building Energy Index (BEI) have been implemented into IES' main dynamic thermal simulation software IES Virtual Environment (IES VE). This enables calculations of the CEI and BEI to be accomplished effectively and quickly. All the inputs required for generating the CEI are simply weather data of a particular location and building hours of use. IES VE provides a worldwide range of hourly weather data. A standard format of weather file - EnergyPlus Weather (EPW) is employed for this purpose. It is also possible to convert other formats to these formats using third party products.

Furthermore, the implementation of the CEI and BEI is accomplished through the IES VE-Navigator tools under 'Climate Index' session, which offer an easy to use workflow system, step-by-step guidance, reports, a built-in Quality Assurance system and analysis automation. The IES VENavigators share an integrated interface with VE-Gaia and VE-Pro and work in conjunction with these tools or can stand alone.

[Figure 1 approx. here]

\subsection{Test protocols}

In order to validate the $\mathrm{CEI} / \mathrm{BEI}$, we followed the following approach:

Compare the CEl against a previously developed and validated attempt to quantify the 'climatic burden;'

Compare the BEl outputs against the output from a simple parametric building energy simulation tool.

The index chosen for the comparison of CEl is the Mahoney's Table [9]. A detail overview of the chart is presented in Appendix 1. We used DEROB-LTH [21] to compare the outputs from the BEI. Ten types of buildings were simulated to derive their energy use. Appendix 2 shows the details of 
these buildings. Since the energy use of these buildings is a function of the design assumptions, we simulated three types of constructions: 'GREAT,' 'GOOD' and 'POOR' buildings. Assumptions used for each of these types are given in Section 4.2.

\section{Results}

\subsection{Validity of the Climate-Energy Index (CEI)}

The CEI is directly comparable in its approach to Mahoney's Chart [9]. Mahoney's Chart combines Air temperature (AT), Relative Humidity (RH), Wind and precipitation data to gauge the necessity for pre-determined passive / low energy building responses to climate.

However, the purpose of Mahoney's Chart is to propose appropriate design strategies and therefore no attempt is made to combine the disparate quantification of climatic burden (in terms of heating, ventilation, rain protection, etc) into a single number. In order to make our comparison work we needed to convert Mahoney's Chart numbers into a single index.

We used the following approach to derive a single index out of the Mahoney's Chart. Mahoney's Chart has six indices to quantify the 'climatic burden' of a given climate:

$$
\begin{aligned}
& \text { H1 - Ventilation essential } \\
& \text { H2 - Ventilation desirable } \\
& \text { H3 - Rain protection essential } \\
& \text { A1 - Thermal mass essential } \\
& \text { A2 - Outdoor activity possible } \\
& \text { A3 - Heating essential }
\end{aligned}
$$

Based on these indices, the Chart recommends design strategies in terms of the following passive design options:

$$
\begin{aligned}
& \text { ventilation } \\
& \text { rain protection } \\
& \text { thermal mass } \\
& \text { heating }
\end{aligned}
$$


Our rationale for combining these indices into a single Mahoney's Chart number is based on the premise that all six indices cannot be of equal weight. Indices that are termed 'essential' need to have higher weighting than those that are termed 'desirable.' (for example, $\mathrm{H} 1$ and $\mathrm{H} 2$ are not of the same weight; $\mathrm{H} 1$ being an 'essential' criteria should have a higher weightage than $\mathrm{H} 2$ - a desirable criteria). For the purpose of our analysis, we created a modified Mahoney's Chart number $\left(\mathrm{MC}_{\mathrm{m}}\right)$ by multiplying all of the 'essential' criteria by 2 and 'desirable' or 'possible' criteria by 1 , and normalising these to derive a single number:

\section{$M C_{m}=\frac{\left\{\left(H_{1} \times 2\right)+\left(H_{2} \times 1\right)+\left(H_{3} \times 2\right)+\left(A_{2} \times 2\right)+\left(A_{2} \times 1\right)+\left(A_{3} \times 2\right)\right]}{10}$}

Given the fact that the individual indices are quantifying the 'climatic burden' they could be added and our weighting enables the essential criteria to dominate the final result.

$M C_{m}$ was compared with CEI (by simple regression) and the anomalies, if any, were examined against a bioclimatic chart to explain the 'severity' of the climatic load. For this purpose we chose the most widely used bioclimatic chart - Givoni's thermal comfort chart [22]. Givoni's Chart plots monthly maximum/minimum air temperature/relative humidity onto a modified psychrometric chart showing zones of influence of nine passive/active building design options.

Figure 2 shows a comparison of CEI with $\mathrm{MC}_{\mathrm{m}}$ for 14 cities from around the world (see Table 1 for the cities). Weather data for our calculations were obtained from a source independent [23] of the one used for the calculation of CEl:

[Figure 2 approx. Here]

As can be seen from Figure 2 the match between the two indices is very poor. However, the situation improved dramatically when an outlier (in this case, Phoenix, USA) was removed (see Figure 3) 
[Figure 3 approx. here]

The reason for the improvement in Figure 3 is the 'extreme' nature of the climate of Phoenix. Figure 4 plots the monthly weather data for Phoenix on Givoni's Bioclimatic chart. As can be seen from Figure 4, the monthly climatic conditions vary widely (from very hot, dry in July and August daytime to very cold and humid nights in December to February). Thus, any attempt to look at the 'annual' climatic burden will tend to gloss over the extreme variations in monthly climate requirements (i.e. the de-humidification need in the winter will be cancelled by the humidification need in the summer). This can be seen from a comparison of the annual humidification needs of Phoenix with a wetter climate (say, Glasgow) - $0.6 \mathrm{kWh} / \mathrm{yr} / \mathrm{m}^{3} / \mathrm{hr}$ (Phoenix) vs. $0.36 \mathrm{kWh} / \mathrm{yr} / \mathrm{m}^{3} / \mathrm{hr}$ (Glasgow), with the relative humidity of the former varying greatly across the year (Phoenix $=$ from $22 \%$ in June to $51 \%$ in December and January) than the latter (Glasgow= from 74\% in May to 86 in December and January). Similarly other 'mild' climates such Sydney, Australia (Figure 5) have less seasonality and therefore a more uniform 'climatic burden.'

The importance of humidity was underscored by a recent exercise to develop a climate suitability index in the U.S. The index developed by the National Institute of Standards and Technology (NIST) in the U.S. [16] found suitability of natural ventilation to increase the effectiveness of cooling is very dependent on the acceptable humidity range. If a dewpoint limit is used, the increase is significant for a dry climate such as Phoenix but much smaller for humid climates such as Miami [16]. While adaptive comfort standards such as the ASHRAE Standard 55 do not impose a limit on humidity when using the adaptive thermal comfort option, the necessity of limiting humidity for other reasons needs to be considered.

We therefore recommend the following:

1. CEI is a good indicator of the 'climatic burden' imposed on buildings by 'mild' external climates (i.e. climate that have a more predictable variation in their monthly climatic burden on buildings) 
2. Its performance may be improved by examining any data anomaly (especially with respect to 'humidification' and/or 'de-humidification'

3. If point no. 2 does not adequately address CEl's performance in extreme climates (i.e. climates with wider monthly variations) perhaps a weighting factor could be introduced to either increase or decrease the importance of latent energy need (i.e. humidification or de-humidification).

[Figure 4 approx. here]

[Figure 5 approx. here]

\subsection{Validity of the BEI}

The validation of BEl involved simulating the energy performance of the 10 types of buildings

ranging from single family residential buildings to very large office and institutional buildings (shown

in Appendix 2), each building under three construction assumptions:

1. Buildings designed to meet the best practices in the developed world (i.e. assuming an indoor condition where the predicted mean comfort vote - PMV lies within - 0.50 to +1.00 ). This category of buildings is called 'GREAT' buildings;

2. Buildings designed for basic code standards as applicable in most developed countries (e.g. designs fulfilling the adaptive comfort stands - ASHRAE 55 -2004 [24] and is defined by ASHRAE 55: 2004, Figure 5.3 with $80 \%$ acceptability. Such an approach is also allowed in many 'sustainable building' assessment methodologies, for example LEED IEQ 7.1 [25] and Green Star IEQ 9). This category of buildings is called 'GOOD' buildings;

3. Buildings designed for basic standards currently prevalent in the developing world (i.e. within an internal PMV of \pm 1.5 ). This category of buildings is called 'POOR' buildings.

Our approach to validate the BEI was as follows:

1. Compare BEl of the ten different types of buildings shown in Appendix 2 for each of the 14 cities, against building energy performance for 'Poor' and 'Great' buildings

2. Attempt to explain variations

3. Compare all of the BEI values with energy performance estimated by a generic building simulation software outputs

The reason for selecting 'Poor' and 'Great' buildings while dropping 'Good' buildings is to account for the fact that improving building standards everywhere (as discussed in Section 2.2) are progressively mandating such buildings to be the norm. However, the existing building stock, especially in the developing world continues to be 'Poor.' At the other end of the spectrum, the current emphasis on third party accreditation of buildings for their 'sustainability' credentials (such as BREEAM, LEED, etc) 
is invariably pushing the energy performance over and above the current norm; thus 'Great' in our classification. It is to be acknowledged that such efforts are currently 'aspirational' and not yet mandatory in many countries. Nevertheless our comparison of BEl against 'Great' and 'Poor' could show the applicability of the index to both standard and aspirational building design practices.

For the purposes of Task 3 above, we used a parametric building energy simulation software called DEROB-LTH developed by the Lund University, Sweden [21]. DEROB-LTH is capable of simulating the indoor thermal comfort and building cooling/heating energy needs. It needs following climatic inputs:

Outdoor average daily maximum and minimum air temperature; Outdoor average daily maximum and minimum relative humidity; Average daily cloud cover (or total global radiation)

Average monthly rainfall

Figure 6a shows the comparison of energy performance vs. BEI for 'POOR' buildings in the 14 climatic locations selected for the study. As is to be expected the predictive ability of the BEI in terms of a building's energy needs is rather poor $\left(R^{2}=0.403\right)$. BEl's predictive ability improved significantly in the case of 'GREAT' buildings (Figure 6b). The case improves even further when energy performance data for hot, humid locations (Singapore, Miami and Bangkok) for one of the more outlandish designs (a building called M8 - mostly glazed and a design more suited to temperate conditions) is removed (Figure 6c). This is to be expected, given the low likelihood of all design types being constructed in all selected climatic locations. It is therefore safe to say that the $\mathrm{BEl}$ index is a good predictor of the likely energy performance of buildings that fulfils the current best practices in the developed world. In this sense, the BEI therefore fulfils its intended purpose (i.e. a simple and universal predictor of building energy performance of 'sustainable' buildings).

[Figure 6 approx. here] 


\subsection{Robustness of the BEI}

As indicated in the previous section, we compared the BEI values for all 10 buildings in all 14 climatic locations. The rationale for selecting these buildings is that these are considered 'sustainable' on account of their assessed scores under a building sustainable assessment methodology such as the BREEAM. It is highly unlikely that all of these buildings will ever be built in all of the selected locations, given the wide variations in local climate. For example, heavily glazed and un-shaded buildings are highly unlikely to be considered 'sustainable' in a warm, humid climatic context. We therefore removed the unlikely combinations (mainly, those in the hot, humid cities of Miami, Singapore and Bangkok). Figure 7 shows the BEI vs. Energy consumption data for 'Great' buildings in all cities excluding the 'hot, humid' cities (i.e. excl. Miami, Bangkok and Singapore). As can be seen from Figure 7, the predictive ability of BEl is improved even more.

[Figure 7 approx. here]

A possible explanation for this improved predictive ability is the pooled (sensible plus latent) nature of the building energy data used for the exercise. The removal of hot, humid cities from the mix reduces the importance of latent energy needs, thus the improved performance. Such a hypothesis is supported by Figure 8 . Figure 8 a shows the relationship between BEI and sensible building energy need (sensible heating or cooling) while Figure $8 \mathrm{~b}$ shows the BEI vs. Latent building energy needs (humidification and/or dehumidification). The improved $\mathrm{R}^{2}$ values for the former indicate that the BEI is a better predictor of sensible energy needs. This again points to the need for a separate (or a weighted) approach to the problem of moisture, much as the discussion on CEI previously indicated.

[Figure 8 approx. here]

We also analysed the predictive ability of the BEI index of the building energy performance of 'POOR' buildings. Given the global ambitions of the CEI/BEI indices, such a robustness test is important. Most buildings (especially in the developing world) are yet to reach the superior indoor 
thermal environmental standards demanded by the best practice regimes currently in operation. In other words, a vast majority of buildings designed and built in the current context remain within our 'POOR' category and therefore, professionals from around the world will find it of immense value if the BEI index could predict the energy performance of these buildings.

Figure 9 shows a comparison of BEI against building energy performance for all buildings in all cities excluding the three hot, humid cities (Miami, Bangkok and Singapore). It is clear that the predictive ability of the BEl is very good even in the case of 'POOR' buildings. ( $R^{2}$ for 'POOR' and 'GREAT' buildings were 0.9077 and 0.9321 respectively). This further reinforces our earlier conclusion that the BEI index is a very good predictor of the building energy performance, even if the buildings are constructed to a 'POOR' thermal comfort standard.

[Figure 9 approx. here]

\section{Implications and Conclusions}

In this paper we tested the validity of the Climate Energy Index (CEI) and the Building Energy Index (BEI) developed by IES Ltd. We compared the efficacy of the CEI against previously developed and tested climate quantification indices (in this case, the Mahoney's chart). We also analysed the performance of the BEI against three categories of buildings (those conforming to best practice standards in the developed world; basic standards in the developed world and those not conforming to current thermal comfort regulations) for 10 different building types in 14 different cities from around the world. Furthermore, we performed robustness tests in terms of climate and building sub-types as well as latent and sensible energy needs to better understand the performance of the BEI.

Based on our work we could conclude as following:

1. CEl has a good match with previous attempts at quantifying the 'climate burden' on buildings with one exception: Phoenix 
2. The outlier case may be explained by the unusually low humidification energy need for Phoenix and/or the equal weighting given to both the 'sensible' and 'latent' energy loads of a given climate.

3. The BEI seem able to predict well the performance of 'Great' buildings than 'Poor' buildings.

4. The performance of 'Poor' buildings improves dramatically if 'hot, humid' climates are excluded (i.e. Miami, Singapore and Bangkok cases)

Finding (4) above indicates a possible strategy to improve future efforts to develop indices to quantify the climatic burden of climates dominated by dehumidification and is discussed below.

\subsection{Future directions}

The prototype Index has the potential to form the basis of a unique design tool that will allow the comparison of designs worldwide in a simple and independent fashion. As an easy to develop index, the BEI (and the CEI) has the potential to provide a common method to compare the energy performance of buildings (and different design strategies) in different climatic regions.

Given the global aspirations of the $\mathrm{CEI} / \mathrm{BEI}$ approaches, it is necessary to enhance the predictive ability of the BEl in hot, humid climates as well. Based on our results (see Finding 4 above) such improvements might involve developing different weighting factors for latent and sensible energy needs, depending on the climatic conditions. It might also be prudent to increase the 'value' (i.e. weightage) of passive design approaches (i.e. ventilation, thermal mass and perhaps solar radiation) in the building category we have termed as 'POOR.'

\section{Acknowledgements}

Funding for this study was provided by the CIC-Start Online Project (http://www.cicstart.org/), funded by the European Regional Development Fund (ERDF) and the Scottish Government. 


\section{References}

[1] Baird G, Donn MR, Brander, WDS, Aun, CS. 1984. Energy Performance of Buildings. Boca Raton, FL: CRC Press, $202 \mathrm{pp}$.

[2] Yannas S. 1994. Solar energy and housing design, Vol. 1: Principles, Objectives, Design Guidelines. London: Architectural Association Publications

[3] Yannas S. 1990. Passive solar heating and energy efficient housing design, Proc. $2^{\text {nd }}$ European Conference on Architecture, Kluwer, Dordrecht, pp. 548-556

[4] Yannas S. 1996. Energy indices and performance targets for housing design, Energy and Buildings, 23, pp. 237-249

[5] Feist W. 2008. What is a Passive House? Passive House Institute.

http://www.passivhaustagung.de/Passive House E/Passive House in short.html (last accessed 08 October 2010)

[6] Dept for Communities and Local Govt (DCLG). 2006. Code for Sustainable Homes: A step-change in sustainable home building practice. London: DCLG, $31 \mathrm{pp}$ (available at: http://www.planningportal.gov.uk/uploads/code for sust homes.pdf last accessed 08 October 2010)

[7] Acharya PK. 1979. Indian Architecture According to Mänasära-Šilpasästra, Patna, India: Indian India, 268 pp.

[8] Morgan MH. (trans.) 1960. Vitruvius: The Ten Books on Architecture, New York: Dover

[9] Koenigsberger OH, Ingersoll TG, Mayhew A, Szokolay SV. 1974. Manual of Tropical Housing \& Building, Part I: Climatic Design, London: Longman

[10] Pérez-Lombard L, Ortiz J, Pout C. 2008. A review on buildings energy consumption information, Energy and Buildings, 40, pp. 394-398

[11] Emmanuel R. 1995. Energy-conscious urban design guidelines for warm-humid cities: strategies for Colombo, Sri Lanka, J. Architectural \& Planning Research, 12, pp. 58-75

[12] Janda KB, Busch JF. 1994. Worldwide Status of Energy Standards for Buildings. Energy, 19, pp. 27-44

[13] Janda KB. 2009. Worldwide status of energy standards for buildings: A 2009 update. In, proceedings of the European Council for an Energy Efficient Economy (ECEEE) Summer Study. Cote d'Azur, France. June 1-6, 2009, pp. 485-491. Available at: www.eci.ox.ac.uk/publications/downloads/janda09worldwidestatus.pdf, accessed 29.10.2011

[14] Iwaro J, Mwasha A. 2010. A review of building energy regulation and policy for energy conservation in developing countries, Energy Policy, 38, pp. 7744-7755

[15] Axley JW, Emmerich SJ. 2002. A method to assess the suitability of a climate for natural ventilation of commercial buildings, in: Proceedings of the Indoor Air, 2002. Available at: http://fire.nist.gov/bfrlpubs/build03/PDF/b03026.pdf, last accessed 29.12.2011

[16] Emmerich SJ, Polidoro B, Axley JW. 2011. Impact of adaptive thermal comfort on climatic suitability of natural ventilation in office buildings, Energy and Buildings, 43, 2101-2107

[17] Thomsen KE, Wittchen KB. 2008. EUROACE, 2008. European National Strategies to Move Towards Very Low Energy Buildings. Publication No. 2008:07, ISBN: 978-87-563-1329-2, Danish Building Research Institute, Aalborg University. Available at:

http://www.euroace.org/PublicDocumentDownload.aspx?Command=Core Download\&Entryld=107 (last accessed 29.12.2011)

[18] Papa RP, Jota PRS, Assis ES. 2007. Energy index evaluation of buildings in function of the external temperature. In, Proceedings: Building Simulation 2007, pp. 1890-1894. Available at: http://www.ibpsa.org/proceedings/BS2007/p626 final.pdf (last accessed 29.12.2011) 
[19] Hernandez P, Kenny P. 2011. Development of a methodology for life cycle building energy ratings. Energy Policy, 39, pp. 3779-3788

[20] Yang Y, Li B, Yao R. 2010. A method of identifying and weighting indicators of energy efficiency assessment in Chinese residential buildings, Energy Policy, 38, pp. 7687-7697

[21] Kvist H. 1999. DEROB-LTH for Windows, Lund, Sweden: LTH

[22] Givoni B. 1989. Urban Design in Different Climates. World Meteorological Organization Technical Note, WMO/TD- 346, WCAP-10. Geneva: World Meteorological Organization

[23] Weatherbase, 2010. Weather records and averages. Available at: http://www.weatherbase.com/ (last accessed 08 October 2010)

[24] ASHRAE, 2004. ANSI/ASHRAE 55 - 2004: Thermal Environmental Conditions for Human Occupancy. Atlanta, GA: American Society for heating Ventilating and Air Conditioning Engineers (ASHRAE)

[25] US Green Building Council (USGBC), 2011. Leadership in Energy and Environmental Design (LEED) for New Construction, version 2.2. Available at: http://www.usgbc.org/ShowFile.aspx?DocumentID=8868, last accessed 19.02.2012 


\section{Appendix 1 - Mahoney's Chart: an example for Singapore}

\begin{tabular}{|}
\begin{tabular}{|c|c|c|c|c|c|}
\hline Indicator totals from data sheet \\
\hline $\mathrm{H} 1$ & $\mathrm{H} 2$ & $\mathrm{H} 3$ & $\mathrm{~A} 1$ & $\mathrm{~A} 2$ & $\mathrm{~A} 3$ \\
\hline 12 & 0 & 2 & 0 & 0 & 0 \\
\hline
\end{tabular}
\end{tabular}

\section{General recommendations}

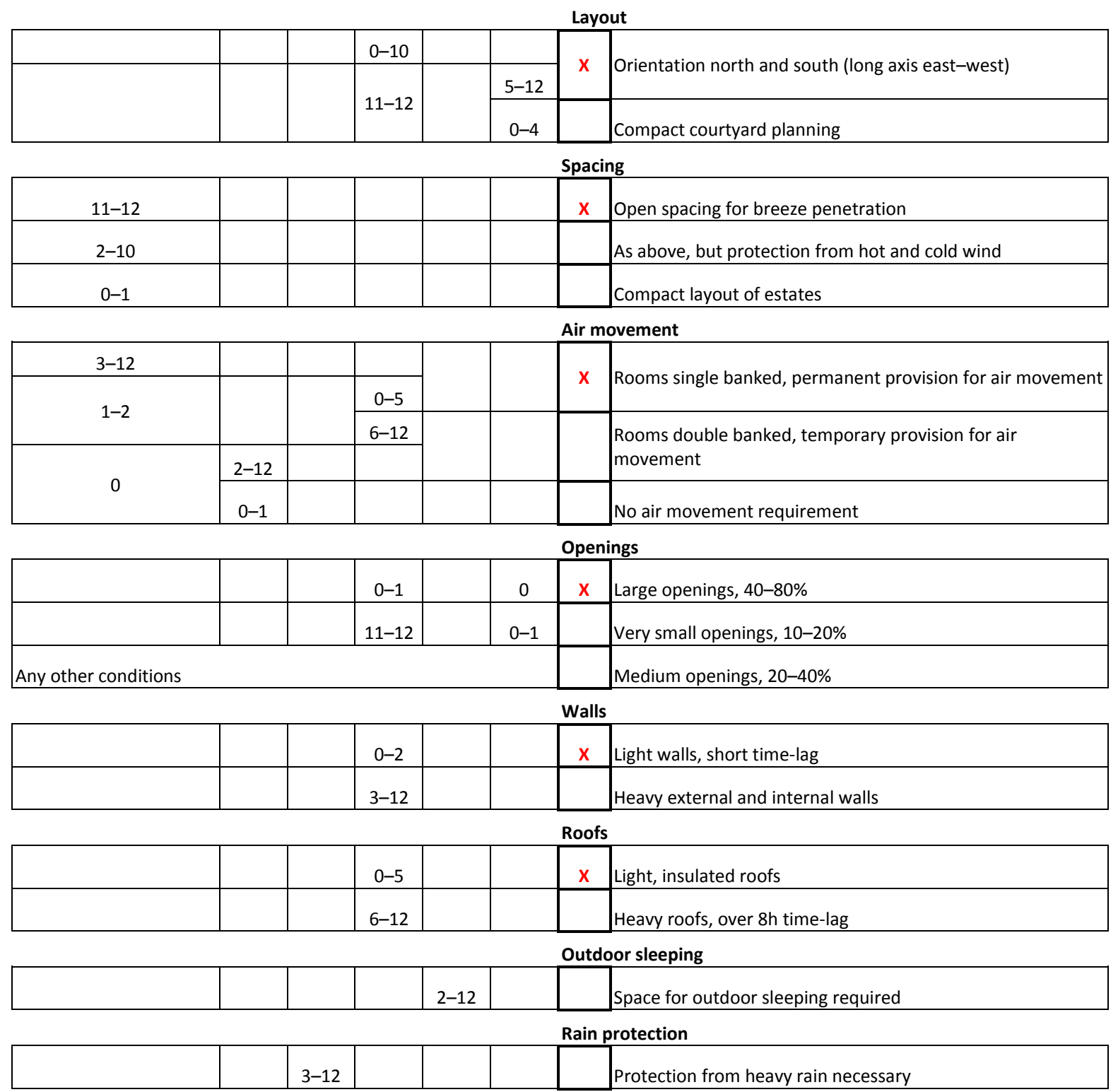




\section{Detailed recommendations}

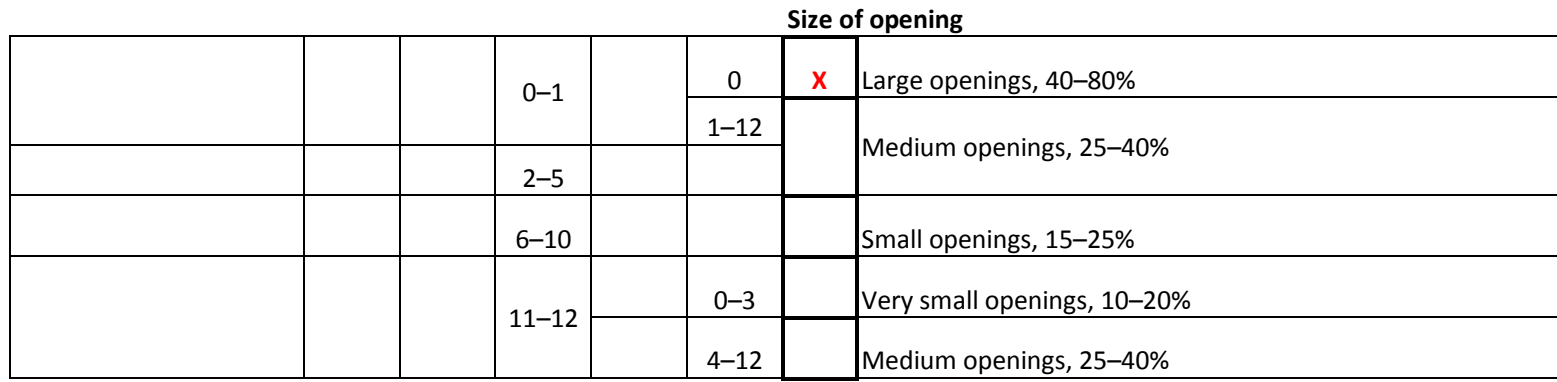

Position of openings

\begin{tabular}{|c|c|c|c|c|}
\hline $3-12$ & & & \multirow{2}{*}{$\mathbf{x}$} & \multirow{2}{*}{ In north and south walls at body height on windward side } \\
\hline $1-2$ & & $0-5$ & & \\
\hline 0 & $2-12$ & & & As above, openings also in internal walls \\
\hline
\end{tabular}

Protection of openings

\begin{tabular}{|l|l|l|l|l|c|c|l|}
\hline & & & & & $0-2$ & $\mathrm{X}$ & Exclude direct sunlight \\
\hline & & $2-12$ & & & & $\mathrm{X}$ & Provide protection from rain \\
\hline
\end{tabular}

Walls and floors

\begin{tabular}{|l|l|l|c|c|c|c|l|}
\hline & & & $0-2$ & & & X & Light, low thermal capacity \\
\hline & & & $3-12$ & & & & Heavy, over 8h time-lag \\
\hline
\end{tabular}

\begin{tabular}{|c|c|c|c|}
\hline \multicolumn{4}{|c|}{ Roofs } \\
\hline \multirow[t]{2}{*}{$10-12$} & $0-2$ & $\mathrm{x}$ & Light, reflective surface, cavity \\
\hline & $3-12$ & & \multirow{2}{*}{ Light, well insulated } \\
\hline \multirow[t]{2}{*}{$0-9$} & $0-5$ & & \\
\hline & $6-12$ & & Heavy, over $8 \mathrm{~h}$ time-lag \\
\hline
\end{tabular}

External features

\begin{tabular}{|l|l|l|l|l|l|l|l|}
\hline & & & & $1-12$ & & & Space for outdoor sleeping \\
\hline & & $1-12$ & & & & $\times$ & Adequate rainwater drainage \\
\hline
\end{tabular}


Appendix 2 - Selected buildings used for the BEI exercise

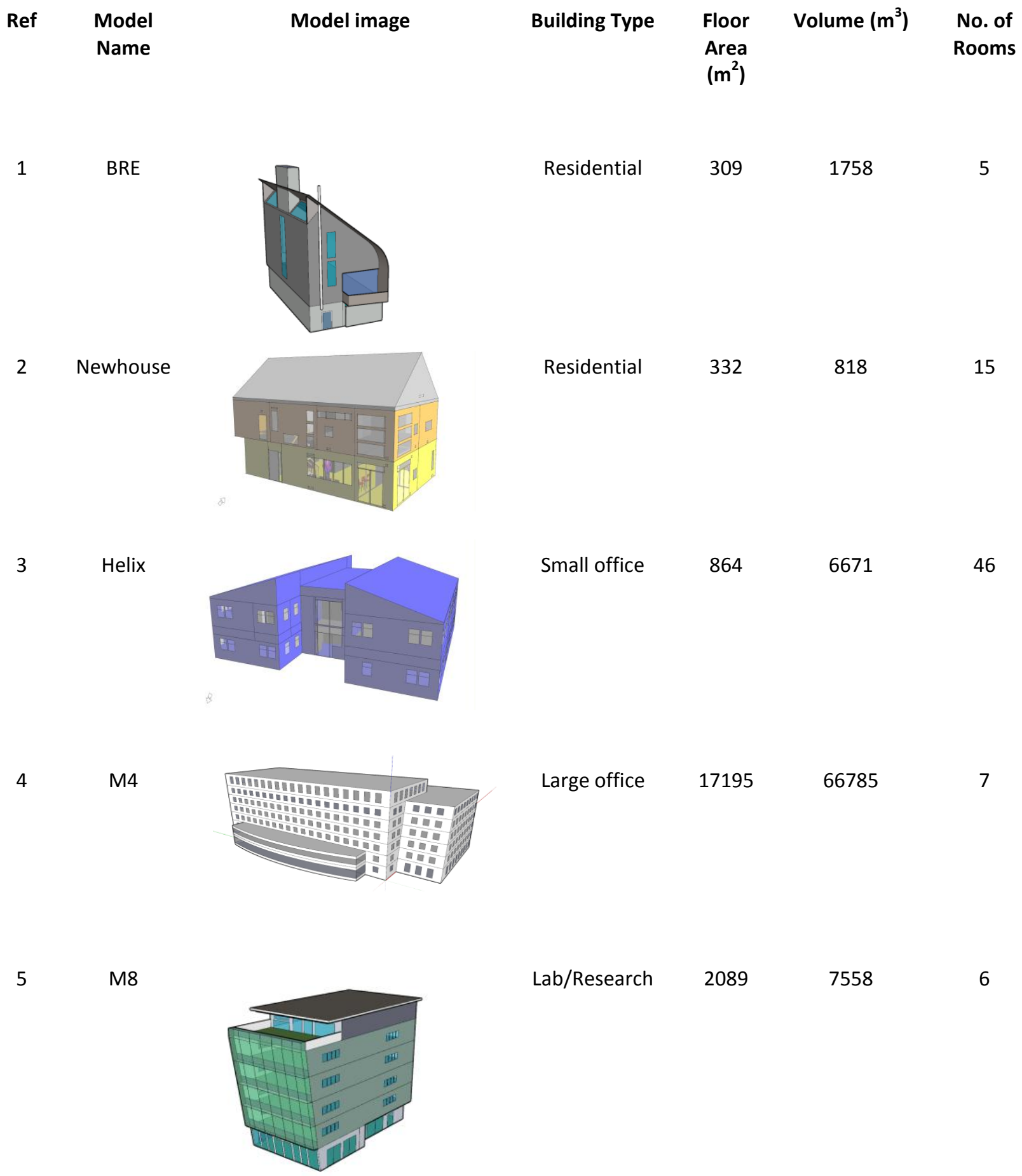




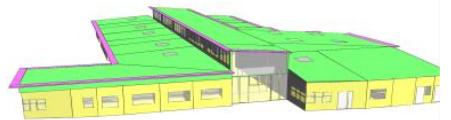

7 Featherstone

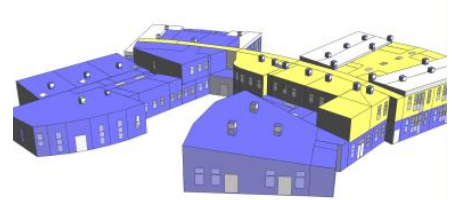

8 Hastings
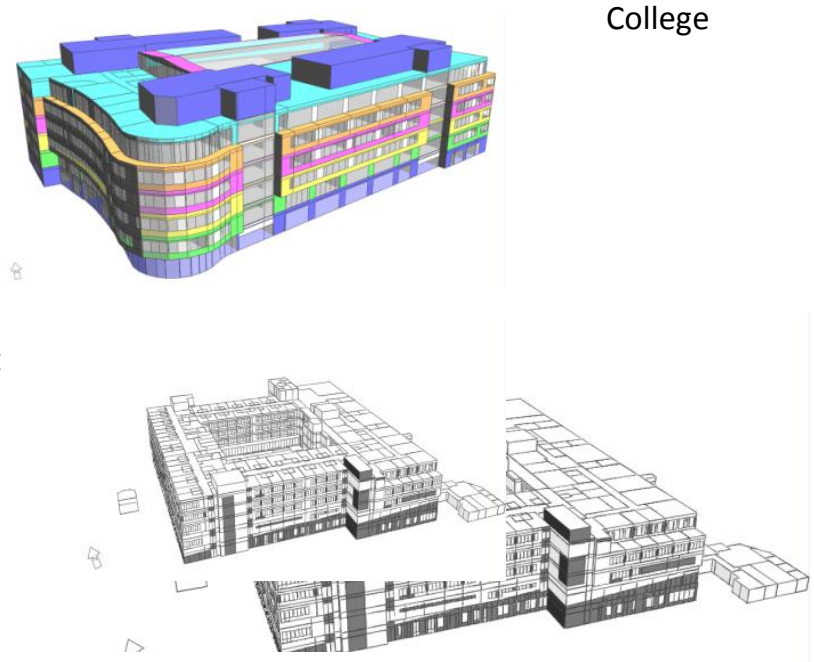

10 Walmart

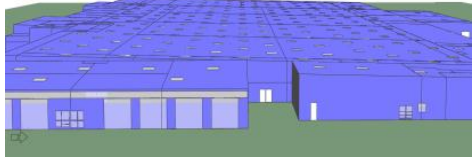

Retail

28641 


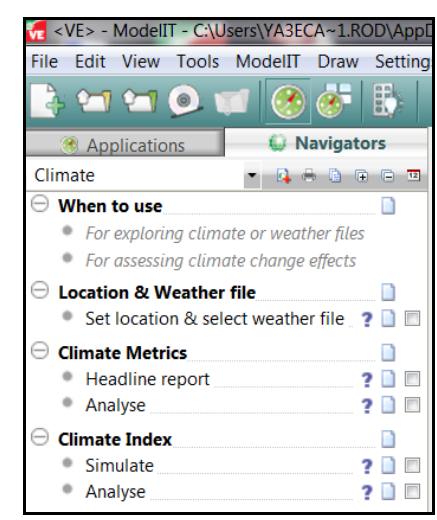

(a) Implementation of CEI and BEI

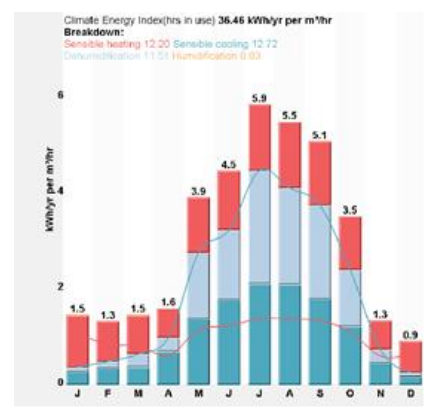

(b) Example of CEI output

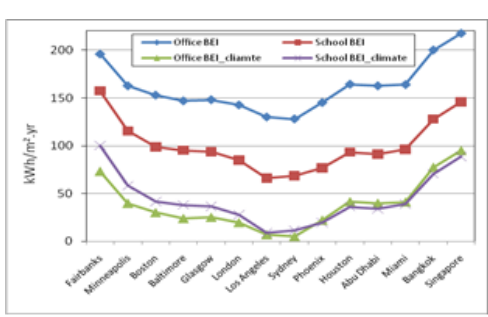

(c) Example of BEl output*

* The BEI output shown here is yet to be fully implemented in the IES-VE platform

Figure 1: Implementation of BEI and CEI in the IES Virtual Environment software 


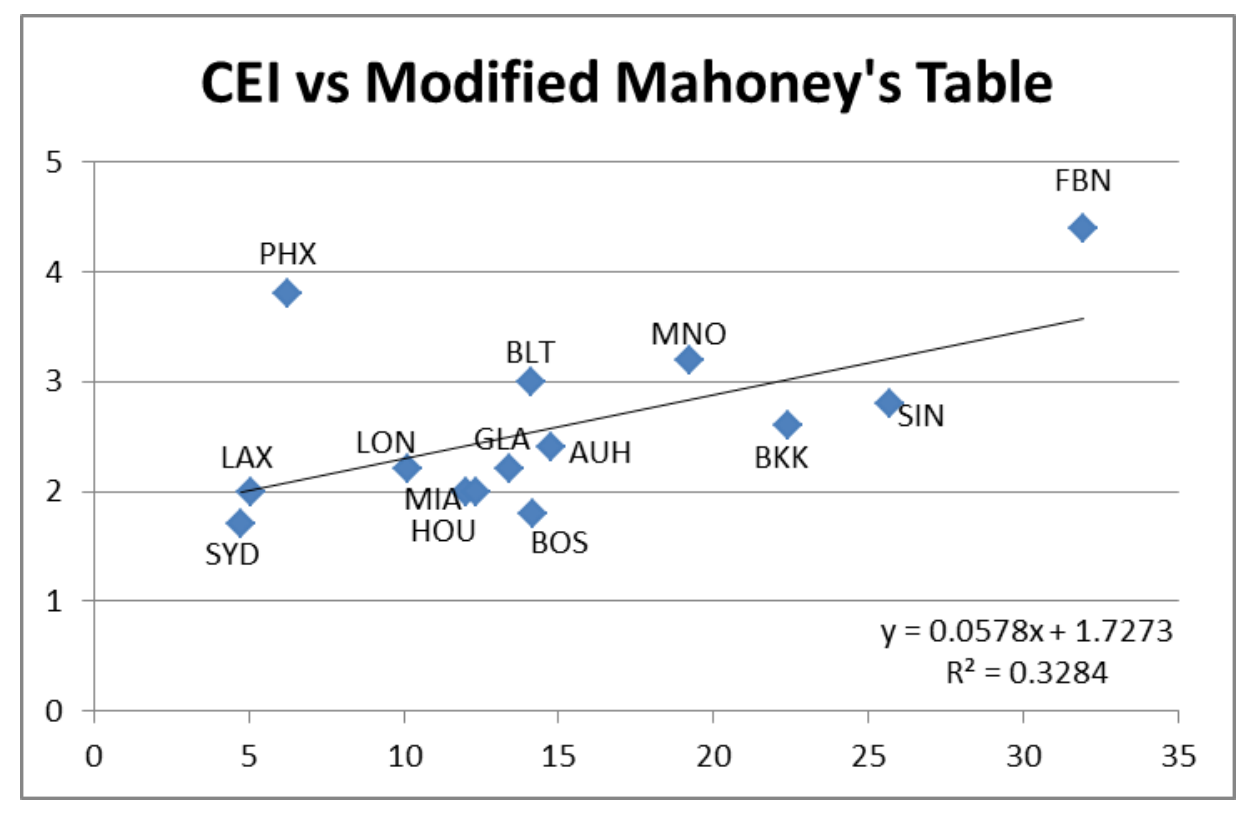

Figure 2: Comparison of 'climate burden' imposed by 14 cities from around the world

Kev:

SYD - Sydney, Australia

LAX - Los Angeles, USA

PHX - Phoenix, USA

LON - London, UK

MIA - Miami, USA

HOU - Houston, USA

GLA - Glasgow, UK

BLT - Baltimore,, USA

BOS - Boston, USA

AUH - Abu Dhabi, UAE

BKK - Bangkok, Thailand

SIN - Singapore

FBN - Fairbanks, USA

MNO - Minneapolis, USA 


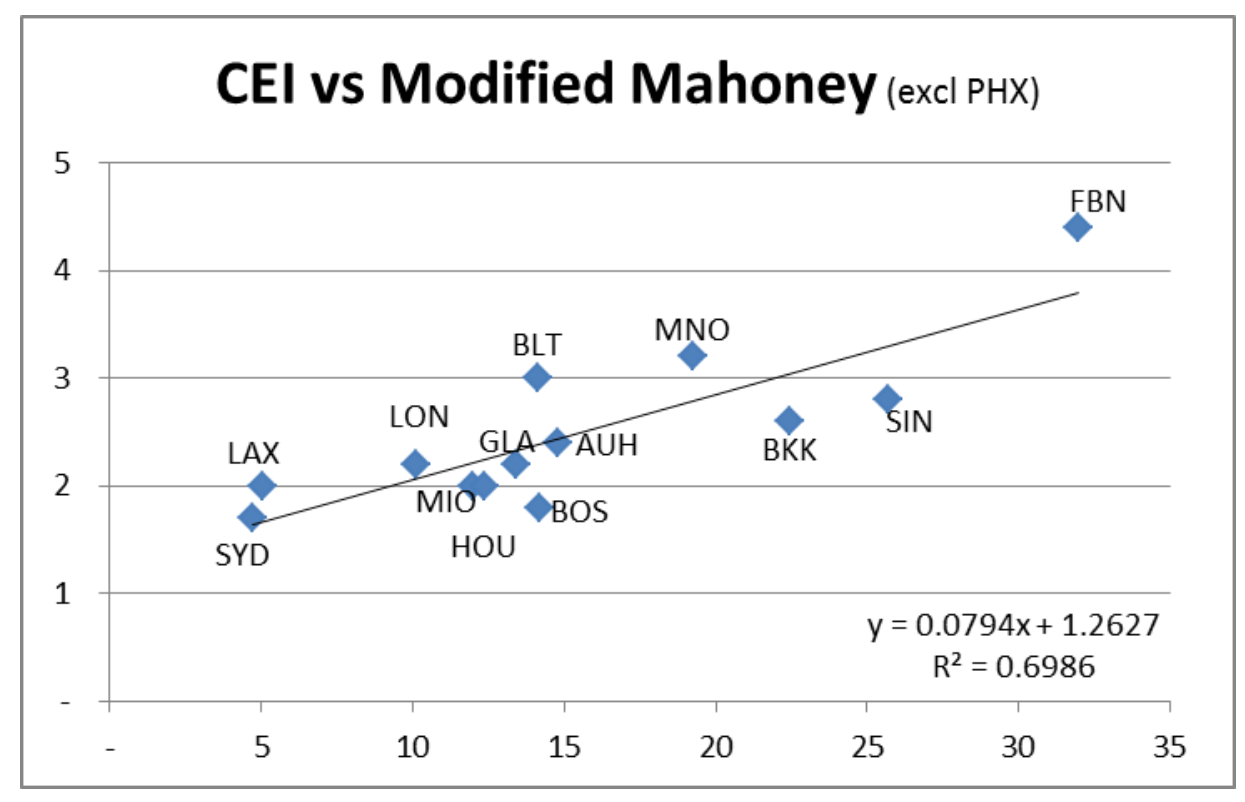

Figure 3: Improved predictive ability of CEI

(Please refer to Figure 2 for Key) 


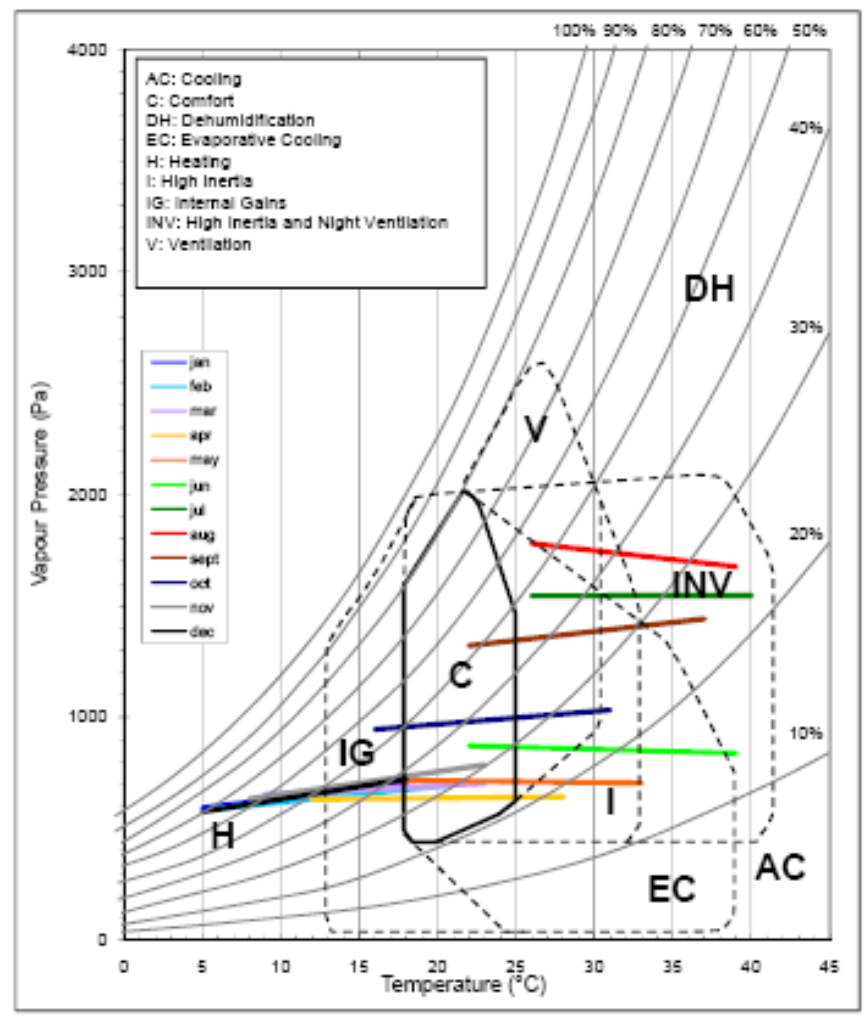

Figure 4: Bioclimatic need in an 'extreme' (Phoenix, USA) climate 

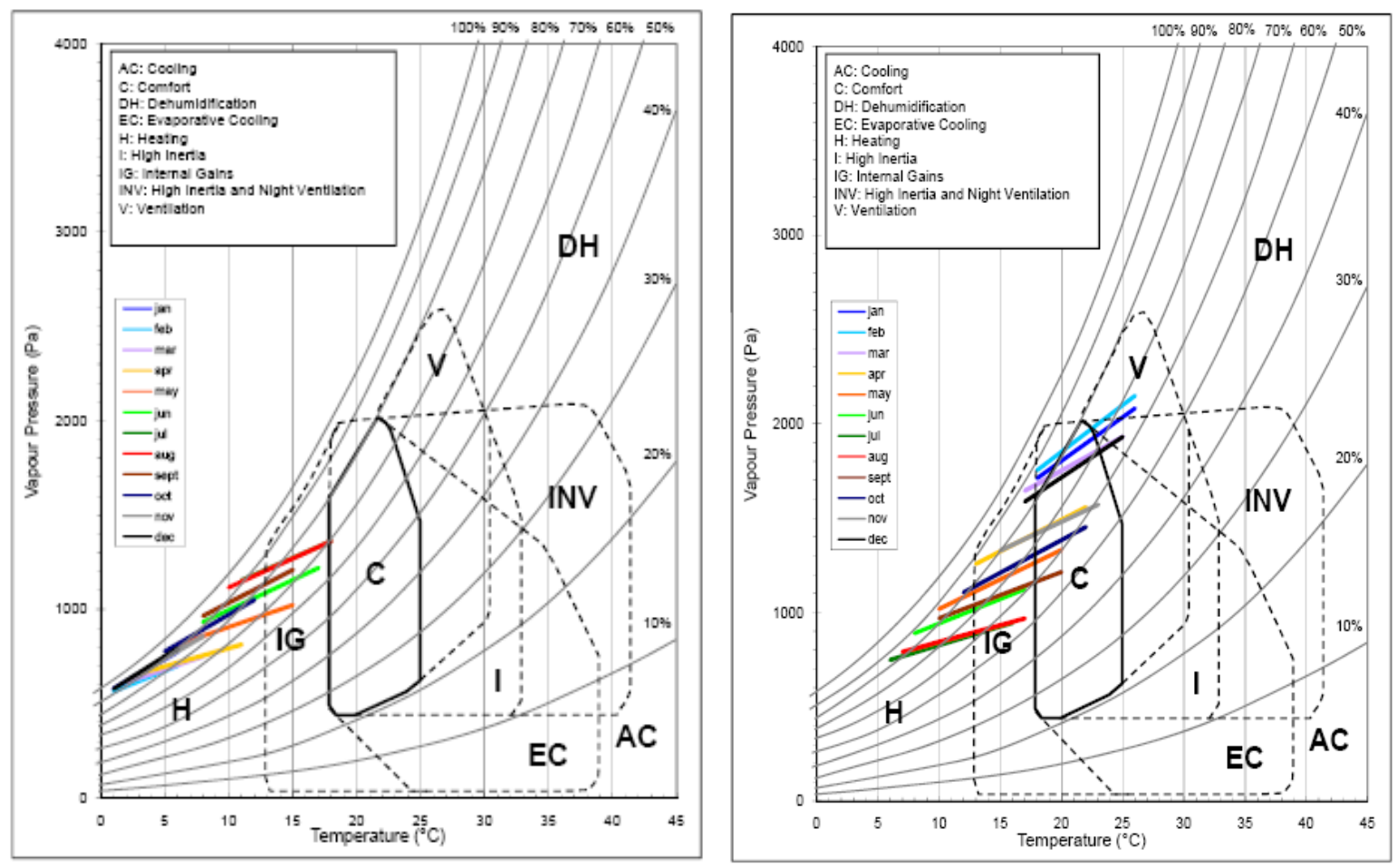

Figure 5: Bioclimatic need in more uniform climates (Glasgow on left and Sydney on right) 

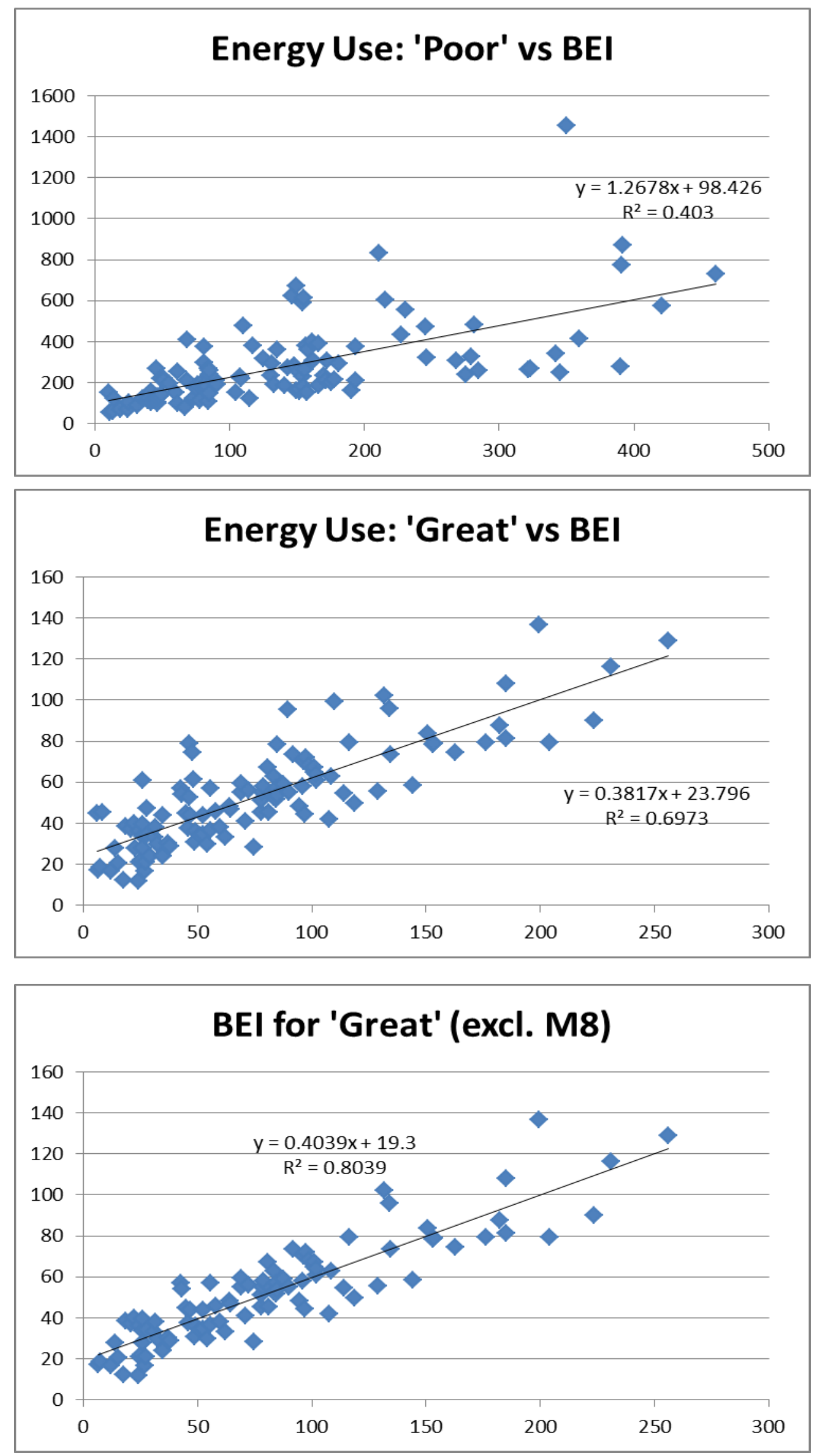

Figure 6: BEI Performance validation 


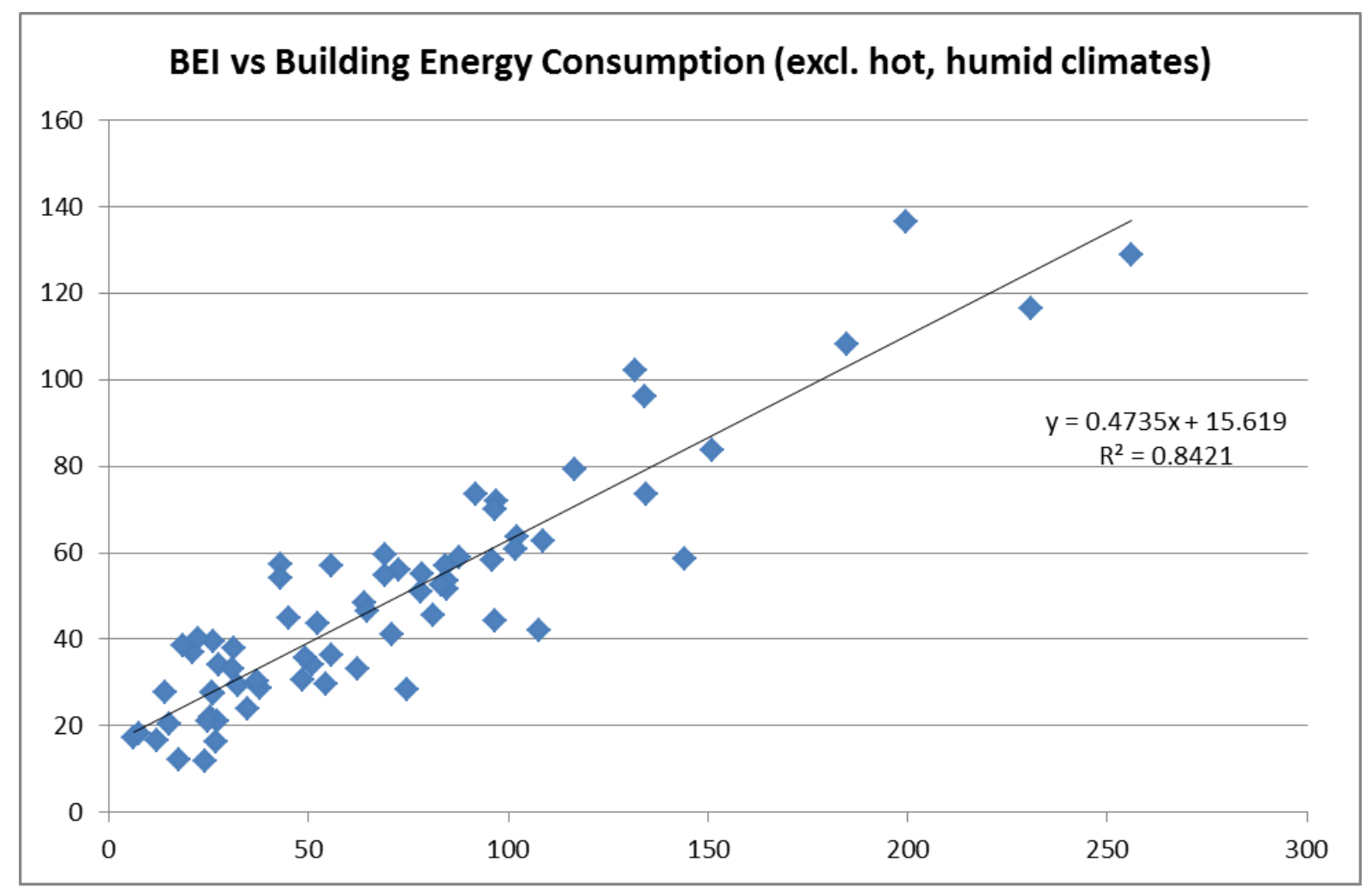

Figure 7: Building energy consumption and BEl excluding hot-humid cities 

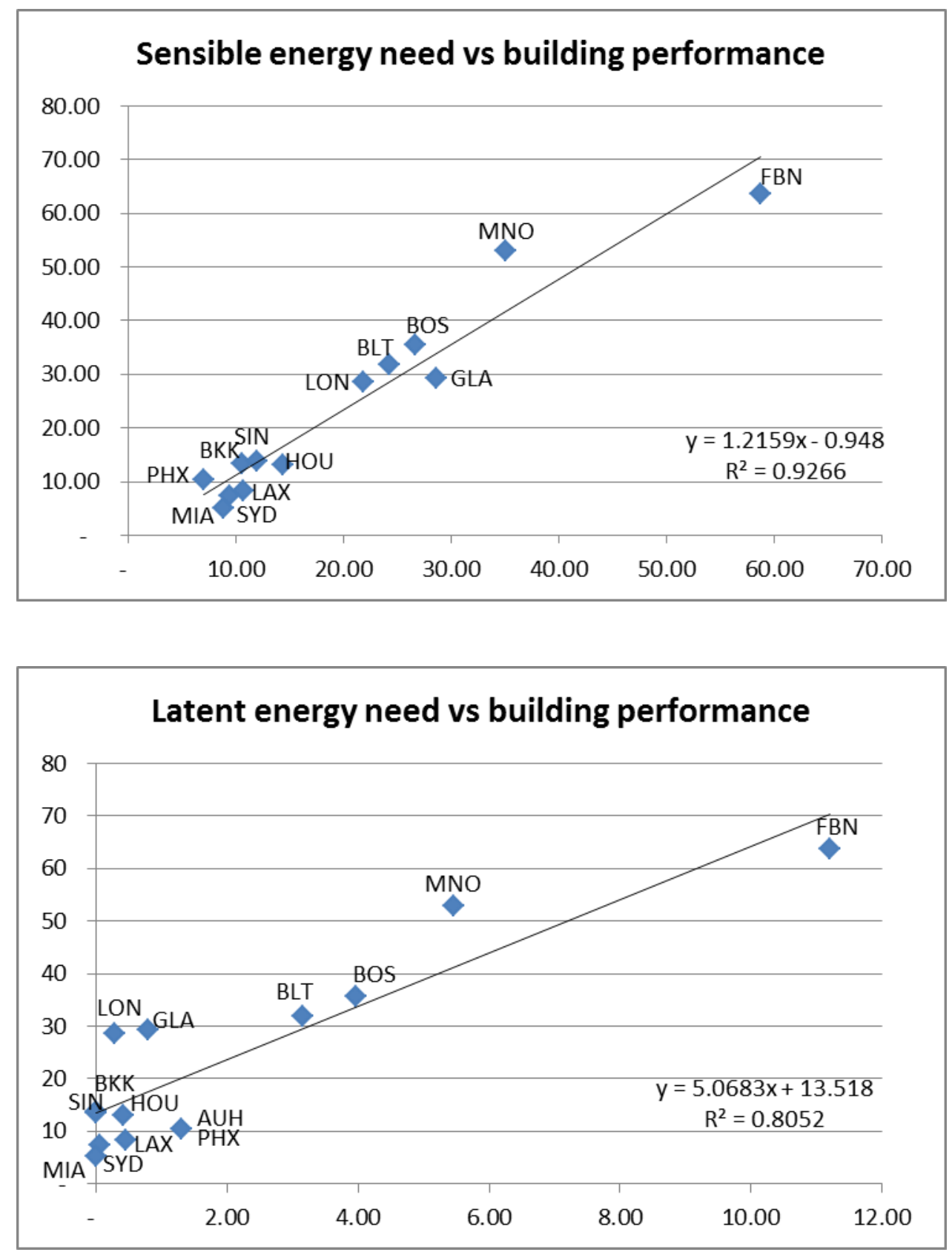

Figure 8: $\mathrm{BEI}$ and the sensible/latent building energy needs

(Please refer to Figure 2 for Key) 

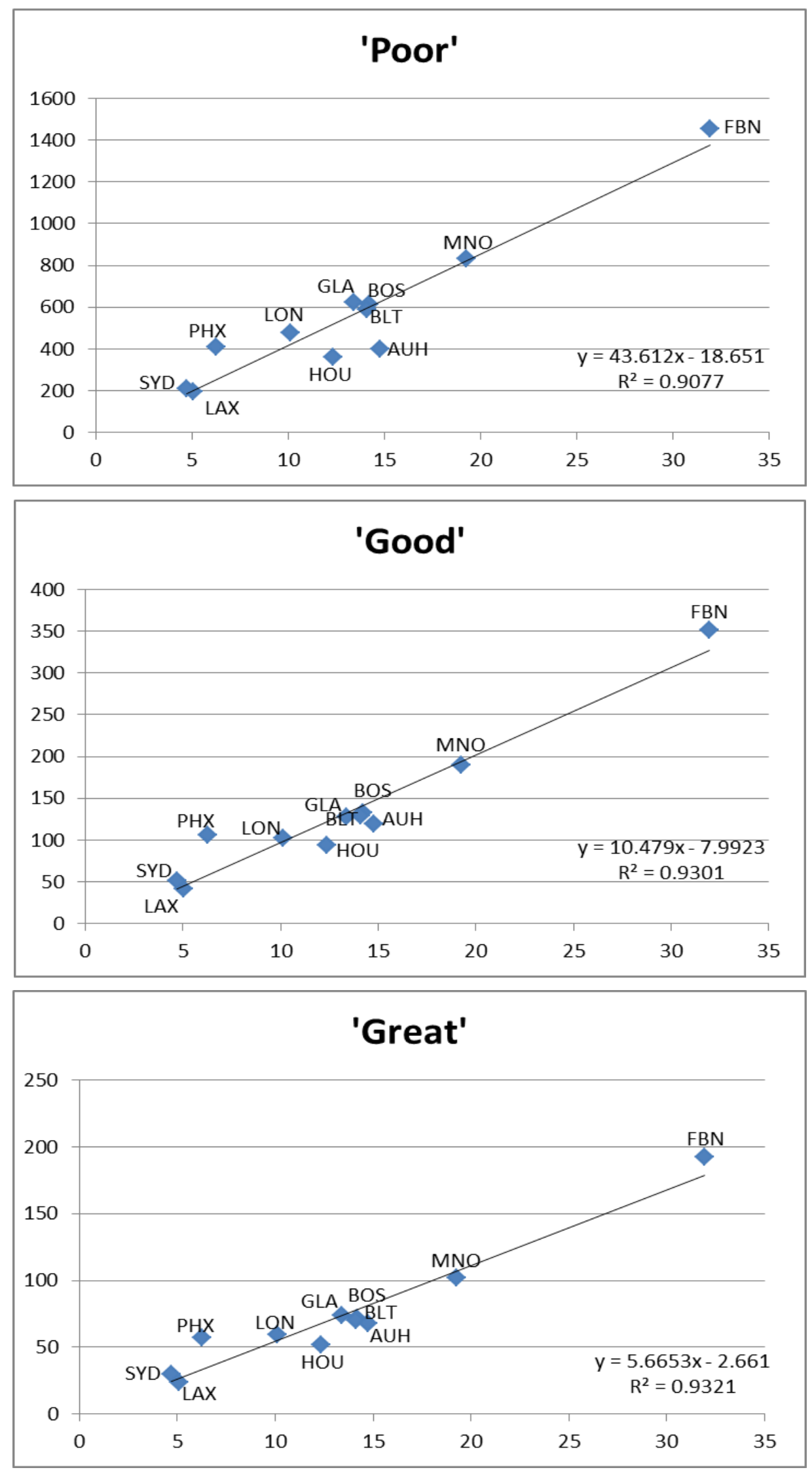

Figure 9: BEl performance in all climates excluding the 'hot, humid' cities (Please refer to Figure 2 for Key) 
